\title{
sciendo
}

\section{Biomechanical Comparisons of One-Legged and Two-Legged Running Vertical Jumps}

\author{
by \\ Wei-Hsun Tai ${ }^{1}$ Li-I Wang², Hsien-Te Peng ${ }^{3}$
}

\begin{abstract}
The purpose of this study was to determine the differences in biomechanical characteristics between one-and two-legged running vertical jumps (1-LRVJ and 2-LRVJ). Ten male college volleyball players voluntarily participated in this study. Two running vertical jumps used in volleyball were randomly performed. Three trials for each type of the running vertical jump were recorded for each participant. Data were collected using six infra-red Qualisys motioncapture cameras at a 180- $\mathrm{Hz}$ sampling rate and two AMTI force platforms at an 1800-Hz sampling rate. Jump height in the 2-LRVJ was significantly higher than that in the 1-LRVJ $(p<0.05)$. In the take-off phase, knee and hip extension impulses for the 1-LRVJ were significantly greater than those for the 2-LRVJ $(p<0.05)$. These results suggest that the 1-LRVJ produced greater leg stiffness than the 2-LRVJ did. We found that the 1-LRVJ caused greater lower-extremity stiffness and impulse compared to the 2-LRVJ, which is beneficial in the stretch-shortening cycle, and thus the more focus on practicing 1-LRVJs is recommended for coaches and athletes.
\end{abstract}

Key words: volleyball, lower-extremity stiffness, training.

\section{Introduction}

One-legged and two-legged running vertical jumps are often practiced in training programs and performed in volleyball. They are important skills for the spike and block movements used in volleyball. Running vertical jumps involve the stretch-shortening cycle (SSC) (Bobbert et al., 1996; Mikołajec et al., 2012, 2017) and have been shown to be very effective neuromuscular exercises for increasing subsequent force production and concentric contraction before take-off (Cormie et al., 2007; Finni et al., 2000; Komi, 2000; Mikołajec et al., 2017). Additionally, they further improve take-off velocity, power, and vertical jump performance (McCaulley et al., 2007; Ruan and Li, 2010).
Both one- and two-legged running vertical jumps are performed with a highapproach running velocity to reach a great preactivation level to increase muscle activation and tension (Ruan and Li, 2010). In order to improve the ability of tendons and muscles to store and release elastic energy, tendons and muscles have to be exposed to high stretching force movements, such as jump landing, drop jumping, or running vertical jumping, because the storage of elastic energy would be enhanced after high stretch speeds and eccentric force (Finni et al., 2000, 2001; Kyrolainen et al., 2003; Markovic et al., 2004). Previous studies suggested that stiffness of the lower extremity increased in accordance with the

\footnotetext{
1 - School of Physical Education, Quanzhou Normal University, Donghai, Quanzhou City, Fujian Province, China, 362000.

2 - Department of Physical Education and Kinesiology, National Dong Hwa University, No. 1, Sec. 2, Da Hsueh Rd., Shoufeng, Hualien 97401, Taiwan (R.O.C.).

3 - Department of Physical Education, Chinese Culture University, 55, Hwa-Kang Road, Yang-Ming-Shan, Taipei 11114, Taiwan (R. O. C.).
} 
movement activities required (Seyfarth et al., 2002; Stefanyshyn and Nigg, 1998), and appropriate lower-extremity stiffness is needed for efficient utilization of the SSC for optimal performance (Latash and Zatsiorsky, 1993).

A previous study demonstrated differences in ground reaction forces between the one- and two-legged vertical jumps (Jakobi and Chilibeck, 2001). It showed that the ground reaction force of a one-legged vertical jump was greater than that of a two-legged vertical jump, indicating that the one-legged vertical jump receives more stretching force than does the twolegged vertical jump. However, there is an approach or run associated with the one- or twolegged vertical jump in volleyball games and training practices; and the contribution from an individual leg during the one- and two-legged running vertical jump in volleyball has not been revealed. In addition, information regarding the biomechanical characteristics of the different running vertical jump skills is limited.

Therefore, the purpose of this study was to compare the biomechanical variables of oneand two-legged running vertical jumps. It was hypothesized that one-legged running vertical jumps would have greater mechanical output compared to the two-legged running vertical jump.

\section{Methods}

\section{Participants}

Ten male college Division I volleyball players (age: $21.1 \pm 2.2$ years; body mass: $80.7 \pm 7.6 \mathrm{~kg}$; height: $1.85 \pm 0.04 \mathrm{~m}$ ) voluntarily participated in this study. All participants had no prior knee pain or any history of trauma to the lower extremities in the 6 months preceding the experiment. All participants were right-handed. This study was approved by the Ethics Committee of the University, and all athletes provided informed consent prior to participation.

\section{Running vertical jump tasks}

Based on the technique of the volleyball spike jump for the right-handed player, the onelegged running vertical jump (1-LRVJ) consisted of left-leg landing on a force platform and left-leg take-off. The two-legged running vertical jump (2LRVJ) consisted of landing on the force platform with both legs symmetrically and a two-legged take-off. The participants were required to perform the vertical jump following a three-step approach, to run as fast, and to jump as high as possible. In order to analyse the movement that the players would actually use for a spike in a volleyball game, they were allowed to swing their arms while jumping, just as they would in games. A suspended string with a target simulating a real ball was placed directly above the front edge of the force plate on the ceiling. Each participant was instructed to spike the target with his right hand when jumping up into the air and then to land on the force platform.

\section{Experimental procedures}

The participants performed a series of dynamic stretches and volleyball-specific warmup activities for $20 \mathrm{~min}$ and practiced the running vertical jump several times. Thereafter, the 1-LRVJ and 2-LRVJ were completed by the participants in random order. Three trials of each running vertical jump were recorded for each participant. There was a 3-min rest between trials. Each participant wore his own training shoes.

\section{Instrumentation and data collection}

Kinematic and kinetic data were collected using six infra-red Qualisys motion-capture cameras (Oqus 100, Qualisys, Inc., Gothenburg, Sweden) at a $180-\mathrm{Hz}$ sampling rate and two AMTI force platforms (BP600900, AMTI, Inc., Watertown, MA, USA) at an $1800-\mathrm{Hz}$ sampling rate. The cameras and force platforms were synchronized using a Qualisys 64-channel A/D board (Qualisys, Inc., Gothenburg, Sweden).

The kinematic and kinetic data were recorded using the Qualisys Track Manager motion capture and analogue data acquisition system (Qualisys, Inc., Gothenburg, Sweden). Twenty-one retroreflective, spherical markers (19 $\mathrm{mm}$ in diameter) were placed on the sacrum and bilaterally on the anterior superior iliac spine, greater trochanter, thigh, lateral femoral epicondyle, medial femoral epicondyle, shank, lateral malleolus, medial malleolus, second metatarsal head, and posterior aspect of the heel according to the modified Helen-Hayes configuration (substituting regular markers for the wand markers).

\section{Data analysis}

Three-dimensional trajectory data of the markers and raw analogue data of the force platforms were identified within the Qualisys Track Manager and exported to a C3D file format. The C3D files were further imported into the 
MotionMonitor software (Innovative Sports Training, Inc., Chicago, IL, USA) for data analyses. The kinematic and kinetic data were filtered by a low-pass Butterworth digital filter at a cut-off frequency of $12 \mathrm{~Hz}$ (Bisseling and Hof, 2006; Ford et al., 2005).

Approach velocity was defined as the sacrum velocity. The duration from the initial foot-contact on the force platform to the toe-off was defined as the support phase. The support phase was separated into the landing phase and the take-off phase based on maximum knee flexion. The landing phase was defined from the initial footcontact to maximum knee flexion, whereas the take-off phase was defined from maximum knee flexion to the toe-off. The initial foot-contact and toe-off were determined by the $20 \mathrm{~N}$ thresholds of the vertical ground reaction force (vGRF). Data from the left leg were used for analyses.

The hip, knee, and ankle flexion angles were calculated from a built-in joint coordinate system of the MotionMonitor software. Joint angles were defined as zero radians at full extension. The joint moment was calculated from the kinematic and force data using inverse dynamics for each trial, as described by Winter (2009). The moment was defined with positive values when the extensors were concentrically contracted. The joint impulse was calculated from the integration of the moment-time curve (JMdt; M: joint moment; dt: duration time). Joint stiffness was calculated from the sagittal plane joint angle and moment using a rotational spring model (Farley et al., 1998; Stefanyshyn and Nigg, 1998). Mean joint stiffness throughout the support phase was defined as the slope of a least-square linear regression line of the joint moment-angle curve $[y=a x+b$ ( $a=$ slope, ie. mean joint stiffness, $b=$ intercept)] (Butler et al., 2003; Ford et al., 2010). The coefficient of determination $\left(\mathrm{r}^{2}\right)$ was calculated to evaluate the linearity of the joint moment-angle curve (Ford et al., 2010). The knee moment was converted to a positive value for consistency with the joint moment-angle curve of the ankle and hip. Jump height was calculated using the formula: $\mathrm{gT}^{2} / 8$ (g $=9.81 \mathrm{~m} / \mathrm{s}^{2} ; \mathrm{T}=$ flight time after take-off).

vGRF was normalized to body mass (BM). The joint moment and impulse were normalized to body mass $\times$ body height $(\mathrm{BM} \cdot \mathrm{BH})$. The jump height was normalized to the percentage of body height $(\% \mathrm{BH})$. Data were averaged across the three trials for each running vertical jump.

\section{Statistical analysis}

Statistical analysis was performed using SPSS 14.0 for Windows (SPSS, Inc., Chicago, IL, USA). Descriptive statistics (mean \pm standard deviation, $\mathrm{SD})$ were used to determine characteristics of participants. The normality of continuous data was assessed with the Kolmogorov-Smirnov test. Comparisons of the one- and two-legged running vertical jump differences in biomechanical variables were performed using analysis of covariance (ANCOVA) adjusted for the approach velocity. Significance was set at $\alpha=0.05$.

\section{Results}

Approach velocity, peak vGRF, vGRF impulse for the landing and take-off phases; ankle plantar flexion, knee extension, and hip flexion impulse for the landing phase; knee extension and hip flexion, impulse of the landing phase, knee and hip extension impulse of the take-off phase of the 1-LRVJ were significantly greater than those of the 2-LRVJ. Nevertheless, the jump height for the 1-LRVJ was significantly smaller than that for the 2-LRVJ (Table 1). Additionally, ankle, knee, and hip joint stiffness for the 1-LRVJ was significantly greater than that for the 2-LRVJ (Table 2).

\section{Discussion}

The purpose of this study was to compare the biomechanical characteristics of one- and twolegged running vertical jumps. The major finding was that the approach velocity, peak vGRF, vGRF impulse of the landing and take-off phase, joint impulse and joint stiffness of the leg during the one-legged running vertical jump were greater than those of the two-legged running vertical jump. However, jump performance for the onelegged running vertical jump was lower than that for the two-legged running vertical jump.

Results of the current study suggested that a one-legged running vertical jump, on the dominant leg, could induce greater muscle activation than a two-legged running vertical jump. Previous research indicated that high approach velocity was associated with increased stiffness of the lower extremity during jumping (Seyfarth et al., 2002; Stefanyshyn and Nigg, 1998). Moreover, the muscle activation level can be increased with increased leg stiffness (Ruan and $\mathrm{Li}, 2008$ ). 


\begin{tabular}{|c|c|c|c|}
\hline \multicolumn{4}{|c|}{ Kinematic and linetic data } \\
\hline & 1-LRVJ & 2-LRVJ & $\mathrm{p}$ \\
\hline Approach velocity $(\mathrm{m} / \mathrm{s})^{*}$ & $2.93(0.56)$ & $2.50(0.22)$ & 0.044 \\
\hline Jump height $(\% \mathrm{BH})^{*}$ & $0.19(0.03)$ & $0.29(0.04)$ & $<0.001$ \\
\hline Peak GRF $(\mathrm{BM}) *$ & $3.02(0.38)$ & $1.63(0.19)$ & $<0.001$ \\
\hline GRF impulse of landing phase $(\mathrm{BM} \cdot \mathrm{s})$ * & $60.14(4.37)$ & $37.69(4.42)$ & $<0.001$ \\
\hline GRF impulse of take-off phase $(\mathrm{BM} \cdot \mathrm{s}){ }^{*}$ & $46.80(6.22)$ & $36.34(4.30)$ & 0.004 \\
\hline $\begin{array}{l}\text { Ankle plantarflexion impulse of landing } \\
\text { phase }[(\mathrm{BM} \cdot \mathrm{s}) / \mathrm{BH}]\end{array}$ & $1.55(0.49)$ & $1.21(0.50)$ & 0.186 \\
\hline $\begin{array}{l}\text { Knee flexion impulse of landing phase } \\
\qquad[(\mathrm{BM} \cdot \mathrm{s}) / \mathrm{BH}]^{* a}\end{array}$ & $-4.26(0.60)$ & $-3.33(0.66)$ & 0.007 \\
\hline $\begin{array}{l}\text { Hip flexion impulse of landing phase } \\
\qquad[(\mathrm{BM} \cdot \mathrm{s}) / \mathrm{BH}]^{*}\end{array}$ & $2.49(1.02)$ & $1.44(0.41)$ & 0.010 \\
\hline $\begin{array}{l}\text { Ankle plantarflexion impulse of the take- } \\
\text { off phase }[(\mathrm{BM} \cdot \mathrm{s}) / \mathrm{BH}]\end{array}$ & $2.77(0.49)$ & $2.52(0.40)$ & 0.243 \\
\hline $\begin{array}{l}\text { Knee flexion impulse of the take-off phase } \\
\qquad[(\mathrm{BM} \cdot \mathrm{s}) / \mathrm{BH}]{ }^{* a}\end{array}$ & $-3.41(0.49)$ & $-2.78(0.44)$ & 0.015 \\
\hline $\begin{array}{l}\text { Hip flexion impulse of the take-off phase } \\
\qquad[(\mathrm{BM} \cdot \mathrm{s}) / \mathrm{BH}]^{*} \mathrm{a}\end{array}$ & $-0.03(0.58)$ & $0.55(0.33)$ & 0.020 \\
\hline
\end{tabular}

*significant difference found ( $p<0.05)$; ' negative flexion impulse values denote an extension impulse. Data are presented as the mean (standard deviation). 1-LRVJ, one-legged running vertical jump; 2-LRVJ, two-legged running vertical jump; BH, body height; BM, body mass; GRF, ground-reaction force.

\begin{tabular}{|c|c|c|c|}
\hline \multicolumn{4}{|c|}{ Mean joint stiffness throughout the support phase } \\
\hline & 1-LRVJ & 2-LRVJ & $p$ \\
\hline $\begin{array}{l}\frac{\text { Ankle }}{\mathrm{a}[(\mathrm{N} \cdot \mathrm{m}) /(\mathrm{BM} \cdot \mathrm{BH} \cdot \mathrm{rad})]} \\
\mathrm{b} \\
\mathrm{r}^{2}\end{array}$ & $\begin{array}{c}0.18(0.06) \\
180.60(38.40) \\
0.33(0.18)\end{array}$ & $\begin{array}{c}0.12(0.03) \\
103.43(23.89) \\
0.46(0.28)\end{array}$ & 0.015 \\
\hline $\begin{array}{l}\frac{\text { Knee }}{\mathrm{a}[(\mathrm{N} \cdot \mathrm{m}) /(\mathrm{BM} \cdot \mathrm{BH} \cdot \mathrm{rad})]} \\
\mathrm{b} \\
\mathrm{r}^{2}\end{array}$ & $\begin{array}{c}0.43(0.10) \\
300.93(86.00) \\
0.90(0.05)\end{array}$ & $\begin{array}{c}0.20(0.02) \\
169.51(32.48) \\
0.91(0.05)\end{array}$ & $<0.001$ \\
\hline $\begin{array}{l}\text { Hip } \\
\mathrm{a}\left[(\mathrm{N} \cdot \mathrm{m}) /(\mathrm{BM} \cdot \mathrm{BH} \cdot \mathrm{rad}){ }^{*}\right. \\
\mathrm{b} \\
\mathrm{r}^{2}\end{array}$ & $\begin{array}{c}0.20(0.03) \\
-49.41(21.61) \\
0.71(0.18) \\
\end{array}$ & $\begin{array}{c}0.11(0.03) \\
-43.02(17.43) \\
0.65(0.10)\end{array}$ & $<0.001$ \\
\hline
\end{tabular}


Significant stiffness may cause an increase in the stretch speed before touchdown and improve stretch reflex, storage and re-utilization of elastic energy, thereby increasing potentiating of the contractile machinery (Kallio et al., 2004).

Combined with the present results of approach velocity and joint stiffness, it can be surmised that the approach for the one-legged running vertical jump increased lower-extremity stiffness before take-off. Joint stiffness in the onelegged running vertical jump seemed to be beneficial to the SSC for the leg as compared to that of the two-legged running vertical jump. Laffaye et al. (2005) indicated that optimal stiffness could increase jumping performance, whereas low joint stiffness with too much knee and/or ankle flexion during take-off would decrease the effect of the SSC. Greater joint stiffness came from the higher muscle activation level because leg extensor muscles worked more rapidly to finish the eccentric contraction (Comyns et al., 2007) with a greater stretch reflex

Moreover, a one-legged running vertical jump produced a greater vGRF impulse and joint angular impulses of the dominant leg than did the two-legged running vertical jump during landing and take-off phases. Bobbert et al. (1987) indicated that the impulse during the landing phase was for deceleration, whereas the impulse during the take-off phase was for the push-off. The onelegged running vertical jump may require more effort for deceleration; however, it can induce greater exertion for the take-off. This provided the rationale for a greater SSC effect and could be the reason that there may have been greater muscle activation on the one-legged running vertical jump. Although higher vGRF and joint angular impulses during one-legged running vertical jumps might induce greater muscle activation than the two-legged running vertical jump for the leg, jump performance of a two-legged running vertical jump was better than that of a one-legged running vertical jump. The reason could be that both legs together can generate greater vertical ground reaction force and joint angular impulse to lift the body higher than one leg only.

There were some limitations in this study that should be acknowledged. We did not control the approach velocity among participants in the design of the study. However, this was examined via an analysis of covariance (ANCOVA) in SPSS where the approach velocity was the covariate. Moreover, we did not measure muscle activation in these participants; therefore, we could not quantitatively determine the association among the muscles during the running vertical jump. A study with electromyography is needed for such analysis.

\section{Conclusions}

The findings of the current study suggest that a one-legged running vertical jump causes increased lower-extremity stiffness and impulse that would be beneficial to the SSC. It is recommended to practice one-legged running vertical jumps during training. Differences in approach velocity and jump performance reflected the unique skill requirement in a volleyball game in which one-legged running vertical jumping would be beneficial to a quick attack, whereas two-legged running vertical jumping would be beneficial for spike blocking and spiking.

\section{References}

Bisseling RW, Hof AL. Handling of impact forces in inverse dynamics. J Biomech, 2006; 39: 2438-2444

Bobbert MF, Huijing PA, van Ingen Schenau GJ. Drop jumping. I. The influence of jumping technique on the biomechanics of jumping. Med Sci Sports Exerc, 1987; 19: 332-338

Bobbert MF, Gerritsen KG, Litjens MC, Van Soest AJ. Why is countermovement jump height greater than squat jump height? Med Sci Sports Exerc, 1996; 28: 1402-1412

Butler RJ, Crowell HP, Davis IM. Lower extremity stiffness: implications for performance and injury. Clin Biomech, 2003; 18: 511-517

Comyns TM, Harrison AJ, Hennesy LK, Jensen RL. Identifying the optimal resistive load for complex 
training in male rugby players. Sports Biomech, 2007; 6: 59-70

Cormie P, McCaulley GO, Triplett NT, McBride JM. Optimal loading for maximal power output during lower-body resistance exercises. Med Sci Sports Exerc, 2007; 39: 340-349

Farley CT, Houdijk HHP, Van Strien C, Louie M. Mechanism of leg stiffness adjustment for hopping on surfaces of different stiffnesses. J Appl Physiol, 1998; 85: 1044-1055

Finni T, Ikegawa S, Komi PV. Concentric force enhancement during human movement. Acta Physiol Scand, 2001; 173: 369-377

Finni T, Komi PV, Lepola V. In vivo triceps surae and quadriceps femoris muscle function in a squat jump and counter movement jump. Eur J Appl Physiol, 2000; 83: 416-426

Ford KR, Myer GD, Hewett TE. Longitudinal effects of maturation on lower extremity joint stiffness in adolescent athletes. Am J Sports Med, 2010; 38: 1829-1837

Ford KR, Myer GD, Smith RL, Byrnes RN, Dopirak SE, Hewett TE. Use of an overhead goal alters vertical jump performance and biomechanics. J Strength Cond Res, 2005; 19: 394-399

Jakobi JM, Chilibeck PD. Bilateral and unilateral contractions: possible differences in maximal voluntary force. Can J Appl Physiol, 2001; 26: 12-33

Kallio J, Linnamo V, Komi PV. The effects of muscle history on short latency stretch reflex response of soleus muscle. J Electromyogr Kinesiol, 2004; 14: 411-421

Komi P. Stretch-shortening cycle: A powerful model to study normal and fatigued muscle. J Biomech, 2000; 33: $1197-1206$

Kyrolainen H, Finni T, Avela J, Komi PV. Neuromuscular behavior of the triceps surae muscle-tendon complex during running and jumping. Int J Sports Med, 2003; 24: 153-155

Laffaye G, Bardy BG, Durey A. Leg stiffness and expertise during jumping. Med Sci Sports Exerc, 2005; 37: 536-543

Latash ML, Zatsiorsky VM. Joint stiffness: Myth or reality? Hum Mov Sci, 1993; 12: 653-692

Markovic G, Dizdar D, Jukic I, Cardinale M. Reliability and factorial validity of squat and countermovement jump tests. J Strength Cond Res, 2004; 18: 551-555

McCaulley GO, Cormie P, Cavill MJ, Nuzw JL, Urbiztondo ZG, McBride JM. Mechanical efficiency during repetitive vertical jumping. Eur J Appl Physiol, 2007; 101: 115-123

Mikolajec K, Waskiewicz Z, Maszczyk A, Bacik B, Kurek P, Zając A. Effects of stretching and strength exercises on speed and power abilities in male basketball players. Isokinet Exerc Sci. 2012; 20(1): 61-69

Mikołajec K, Maszczyk A, Chalimoniuk M, Langfort J, Gołaś A, Zajc A. The influence of strength exercises of the lower limbs on postural stability: A possible role of the autonomic nervous system. Isokinet Exerc Sci. 2017; 25(2): 79-89

Ruan M, Li L. Influence of a horizontal approach on the mechanical output during drop jumps. Res Q Exerc Sport, 2008; 79: 1-9

Ruan M, Li L. Approach run increases preactivation and eccentric phases muscle activity during drop jumps from different drop heights. J Electromyogr Kinesiol, 2010; 20: 932-938

Seyfarth A, Geyer H, Gunther M, Blickhan RA. A movement criterion for running. J Biomech, 2002; 35: 649655

Stefanyshyn DJ, Nigg BM. Dynamic angular stiffness of the ankle joints during running and sprinting. J Appl Biomech, 1998; 14: 292-299

Winter DA. Biomechanics and motor control of human movement (4th ed.) New York: Wiley, 107-138; 2009

\section{Corresponding author:}

\section{Hsien-Te Peng,}

Department of Physical Education, Chinese Culture University,

55, Hwa-Kang Road, Yang-Ming-Shan, Taipei 11114, Taiwan (R. O. C.).

E-mail: pxd@ulive.pccu.edu.tw 